\title{
Examination of Surface Wear on the Timing Chain Tensioner Depending on the Engine Oil Contamination
}

Petra Kováčiková, Andrej Dubec, Daniela Koštialiková, Mariana Janeková

Faculty of Industrial Technologies in Púchov, Alexander Dubček University of Trenčín. I. Krasku 491/30, 02001

Púchov. Slovakia. E-mail: petra.kovacikova@fpt.tnuni.sk

The given paper deals with the wear of the tensioner which is produced from aluminium alloy and used of the motorcycle timing chain. This component was made due to the unavailability on the spare parts market. The AlMgSi1 alloy was chosen for this purpose, taking into account the requirements for producing of the tensioner. After production, the tensioner was put into operation where its functionality was regularly controlled. The suitability of the selected material was checked after the tensioner was removed. Possible damages and structural changes in the material were assessed using a scanning thermoemission electron microscope. Detection of the chemical composition of foreign particles trapped on the surface of the tensioner from engine oil during the operation was performed by EDS analysis.

Keywords: Aluminium Alloy, Scanning electron microscopy, Energy dispersive spectroscopy

\section{Introduction}

In a four-stroke combustion engine, one of the most important systems is a timing mechanism. This mechanism controls the operation of the valves to ensure that the air-fuel mixture is supplied to the engine and discharging exhaust fumes. The movement of this mechanism is ensured by a crankshaft and subsequently transmitted to the camshafts by a timing chain. To ensure efficient and silent transmission of torque, proper tension of the timing chain is required, achieved by the timing chain tensioner. Insufficient tension of the timing chain due to damage to the tensioner is manifested by increased chain noise and vibration. Ignoring these warning signals often results in the timing chain being skipped and resulting in engine damage. The principle of working the tensioner with lock nut is to manually tighten the chain by unscrewing the shaft with thread and locking the nut. This type of tensioner does not automatically eject, the chain tensioning is done by means of a tensioner manually, while the tension must be checked regularly - ideally every 15 hours. Inadequate tensioning of the timing chain can be prevented by regular inspection. A great advantage of this type of tensioner is its very long lifetime, as it does not cause such widespread wear, which would limit its functionality. Thanks to this advantage it is possible to use it also for highly stressed motorcycles in sport [1]. The investigated tensioner was subjected to operation for 180 hours and subsequently removed from the timing mechanism. The most stressed part of the tensioner with the locknut is the front of the tensioner and therefore this work is focused on the study of its surface wear by the SEM method.

\section{Material characteristics}

The subject tensioner is made of a hardenable aluminum alloy AlMgSi1. This material is used in products requiring a combination of properties such as low weight, good strength and corrosion resistance. It is used in manufacture of transport equipment, in construction, in the food and chemical industries. Improved corrosion resistance under normal atmospheric conditions is possible by applying anodic oxidation [2]. The chemical composition of the AlMgSil alloy is shown in Table 1.

Tab. 1 Chemical composition of the alloy AlMgSi1

\begin{tabular}{|c|c|c|c|c|}
\hline $\mathbf{S i} \mathbf{( \% )}$ & $\mathbf{M g} \mathbf{( \% )}$ & $\mathbf{M n}(\mathbf{\%})$ & $\mathbf{C u} \mathbf{( \% )}$ & $\mathbf{F e} \mathbf{( \% )}$ \\
\hline $0.70-1.30$ & $0.60-1.20$ & $0.40-1.00$ & 0.10 max. & 0.50 max. \\
\hline $\mathbf{C r} \mathbf{( \% )}$ & $\mathbf{Z n} \mathbf{( \% )}$ & $\mathbf{T i} \mathbf{( \% )}$ & Other $\mathbf{( \% )}$ & $\mathbf{A l} \mathbf{( \% )}$ \\
\hline 0.25 max. & 0.20 max. & 0.10 max. & 0.15 max. & remaining \\
\hline
\end{tabular}


The microstructure of the tensioner (Fig. 1) is create by aluminum matrix in which two types of phases are present. These two phases based on the elements $\mathrm{Al}, \mathrm{Fe}, \mathrm{Mn}$ (Fig. 2) and $\mathrm{Al}, \mathrm{Si}, \mathrm{Mg}$ (Fig. 3) [3]. In a detailed view, the rounding of the edges of both types of phases is visible. This indicates that the material has been heat treated prior to further processing [4]. Heat treatment is applied to improve the properties of the alloy. A semiproduct for the tensioner was made by the forming technology because the directed phases are present in the microstructure. Thanks to its microstructure, this material is suitable for dynamically loaded applications [5].

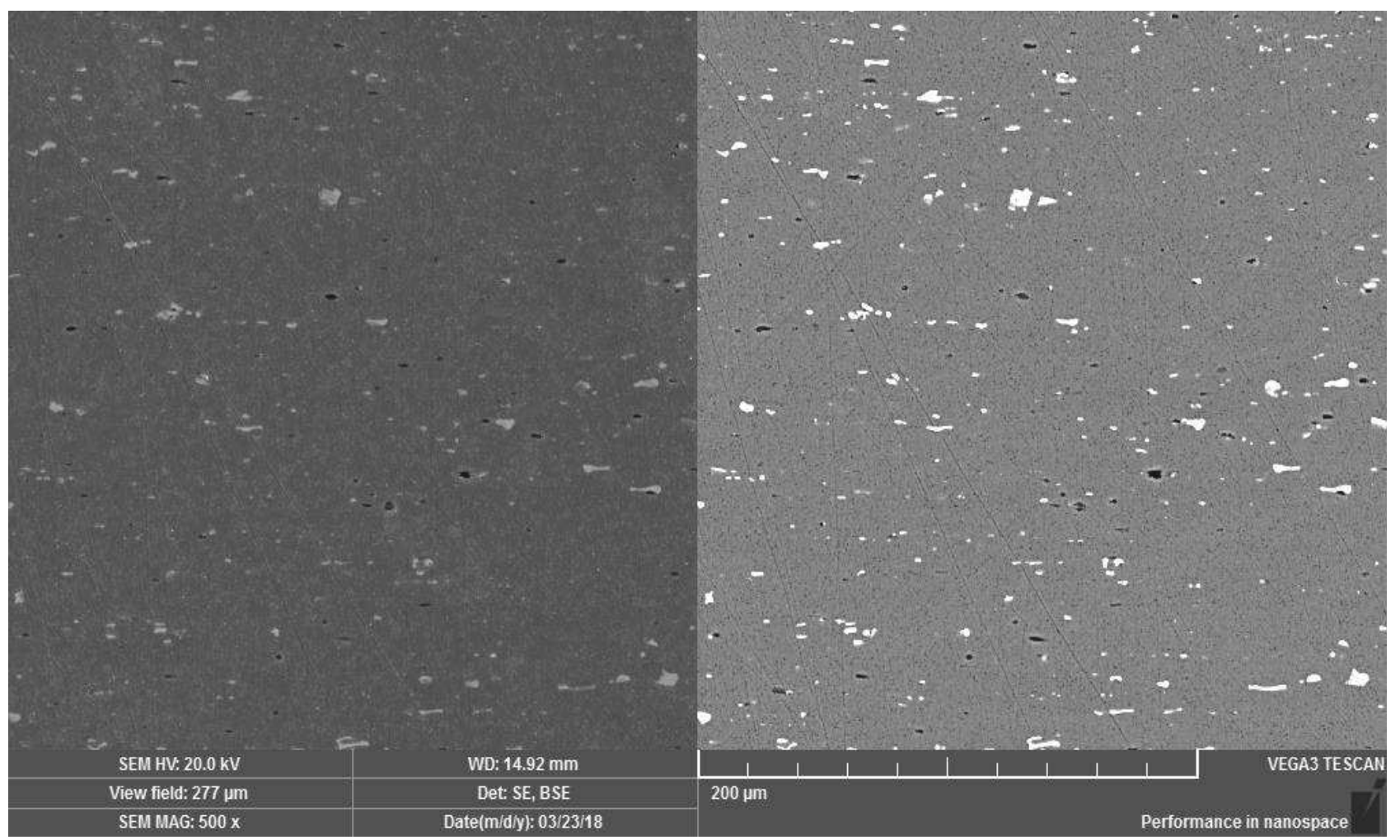

Fig. 1The microstrusture of the tensioner, longitudinal section

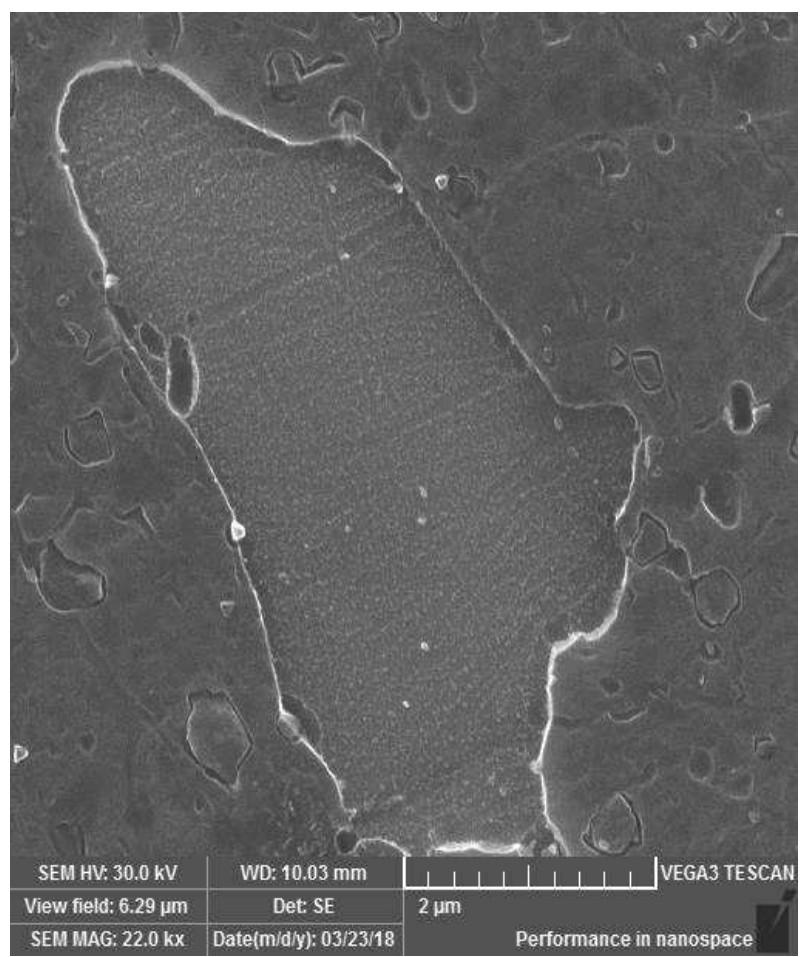

Fig. 2 Phases based on the elements $A l, F e, M n$

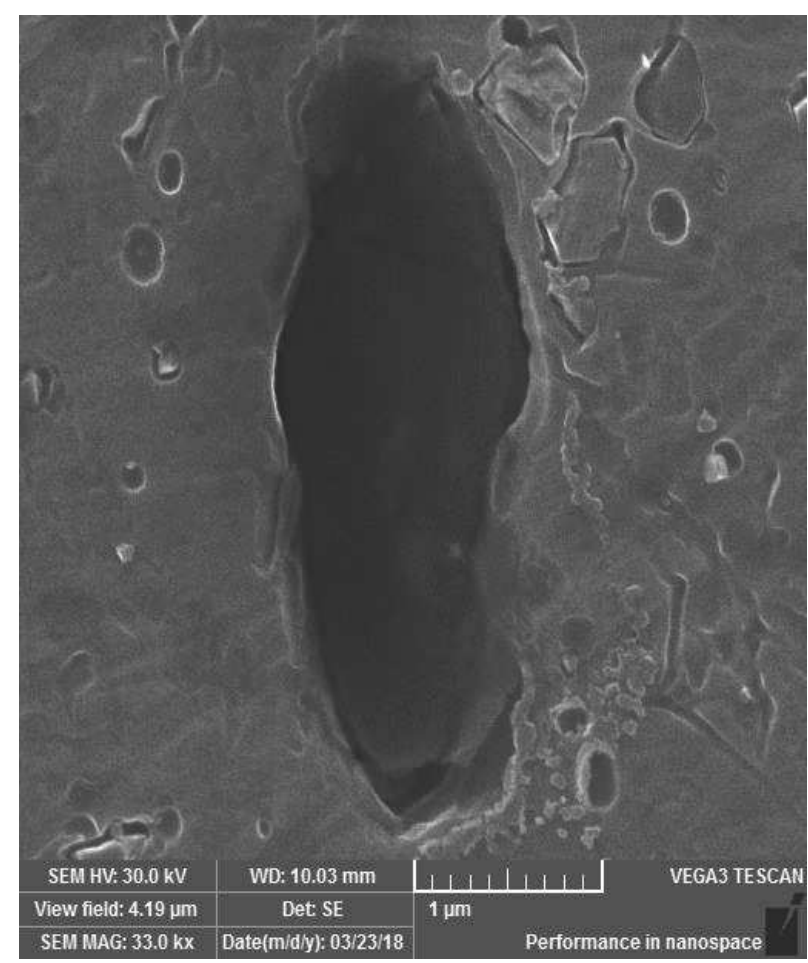

Fig. 3 Phases based on the elements Al, Si, Mg 


\section{Surface wear of the tensioner face}

The front of the tensioner forms a contact surface with the guide which causes it to wear due to cyclic force transmission depending on the timing chain movement. Surface wear resulting from 180 hours of operation was evaluated by SEM and EDS methods. The significant microrelief is visible on the surface of the tensioner face at its edge part in secondary electron mode. This microrelief is caused by the pressing of foreign particles. In the back scatered electron mode, the material contrast of these particles is observable, which are formed by chemical elements with a larger atomic number than the base material of the produced tensioner (Fig. 4). Superficial scratches were also observed at the front of the tensioner. These surface defects are caused by contaminating particles with greater hardness than the base material (Fig. 5) [5,6].

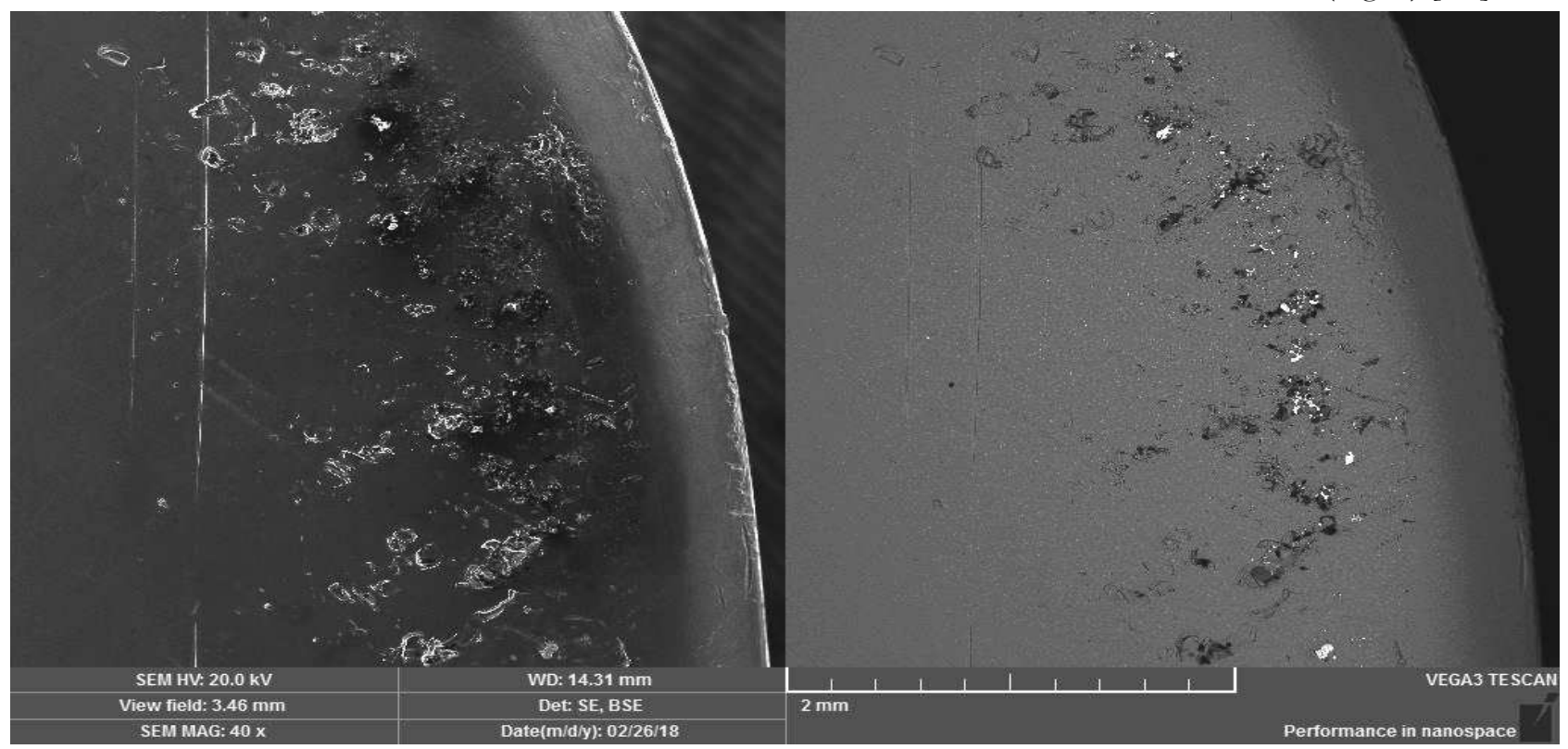

Fig. 4 The front of the used tensioner shaft

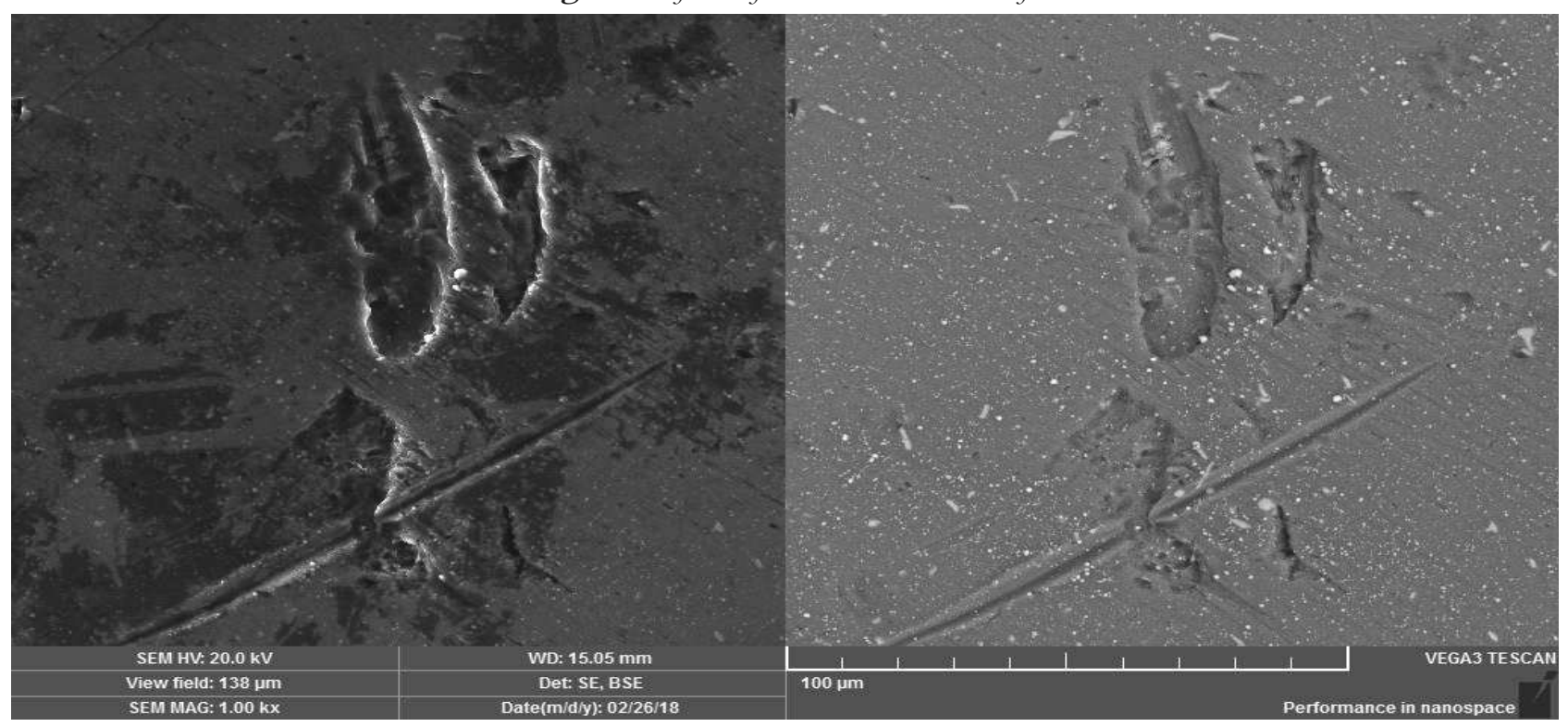

Fig. 5 Superficial scratches at the front of the tensioner

There were also small particles pressed into surface containing nickel, copper and zinc on the edge of the tensioner face. Oil filling of this type of engine serves for lubrication of crankshaft parts and at the same time in the gearbox part of the engine. The particles carried by the engine oil could be released from any parts exposed to abrasions located in these areas. The particles were pressed into the material of tensioner front face by tapping the timing chain guide [7].

The nickel particles (Fig. 6) could be released from the surface of the parts that had been modified to increase surface hardness or to improve sliding properties. This may be due to abrasion of the surface layer of the cylinder, this layer being called Nikasil. The copper-zinc-containing particles (Fig.7) could in turn be 
released from the brass components. Such components are pins located on the control cylinder. They serve for sensing the engaged gear, from the exchange drum pin in the shift mechanism, the gear housing in the starter lever mechanism, the connecting rod shim, or the connecting rod eye housing $[7,8]$.

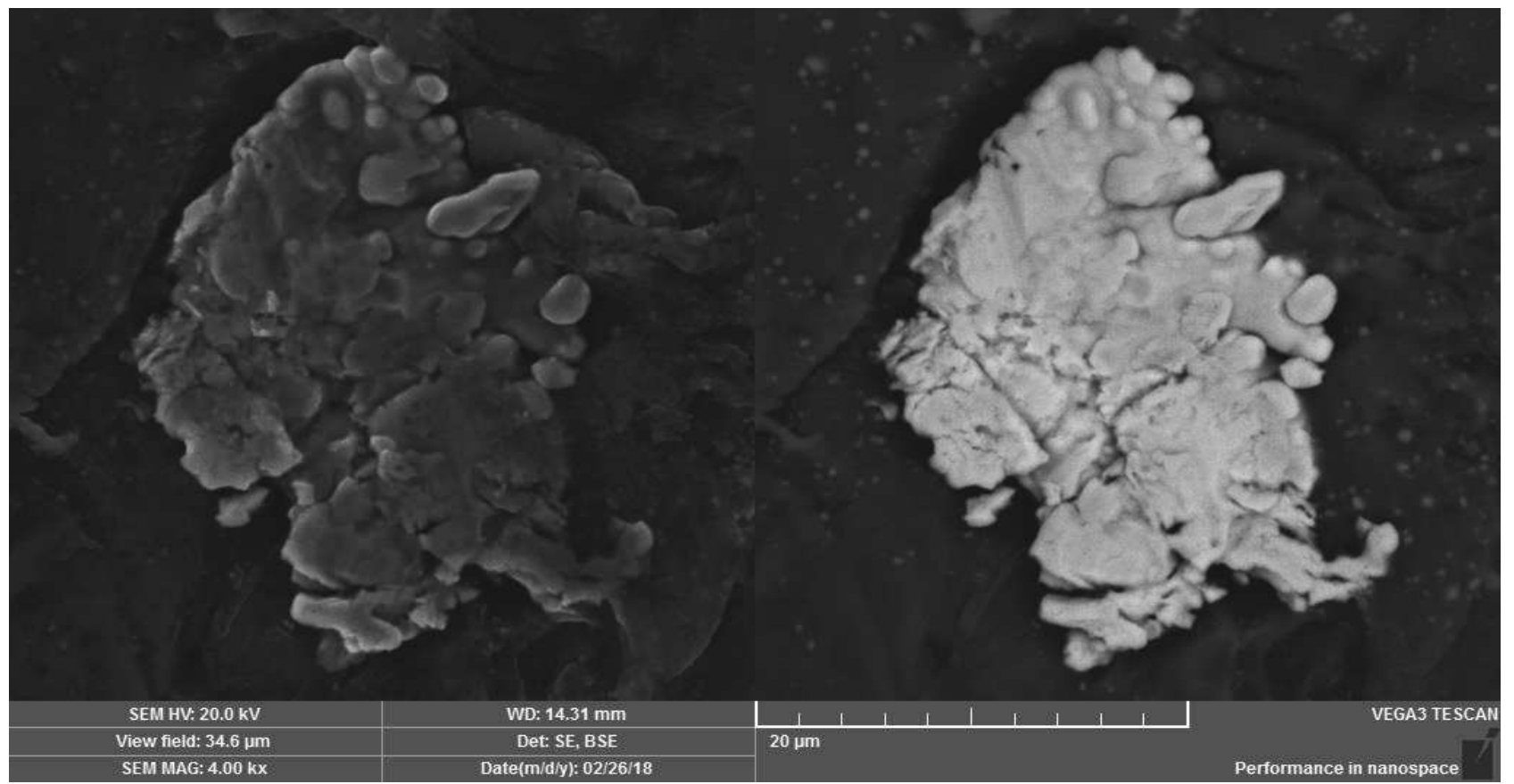

Fig. 6 Particle containing $\mathrm{Ni}, \mathrm{Cu}, \mathrm{Zn}$

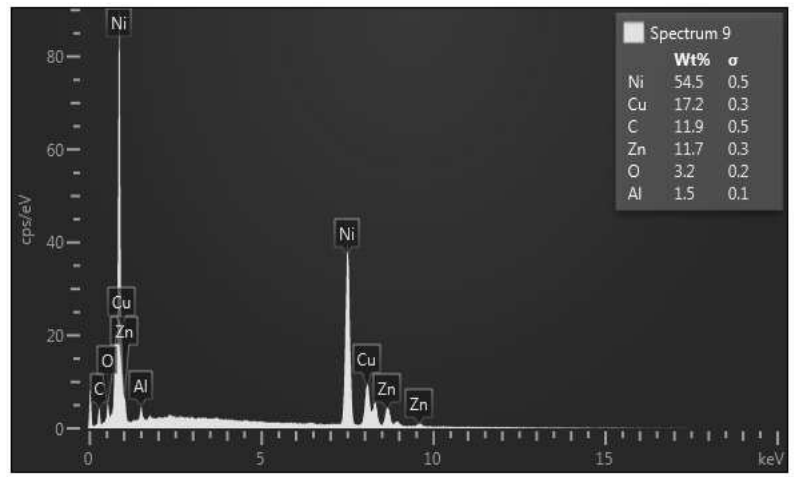

Fig. 7 EDS analysis of particles
A local presence of particles composed primarily of Cr was observed on the shaft head (Fig. 8, 9). These particles were also embedded in the shaft head material. Because of their greater hardness and smaller dimensions, they were pressed into the surface of this material. There is an intermittent contact between the front end of the tensioner and the timing chain guide. Particles on the surface appeared as part of the tensioner material during evaluation in secondary electron mode. The particles could be released from any worn-out engine component present in the engine oillubricated area. These components have a chrome layer on surface [8].

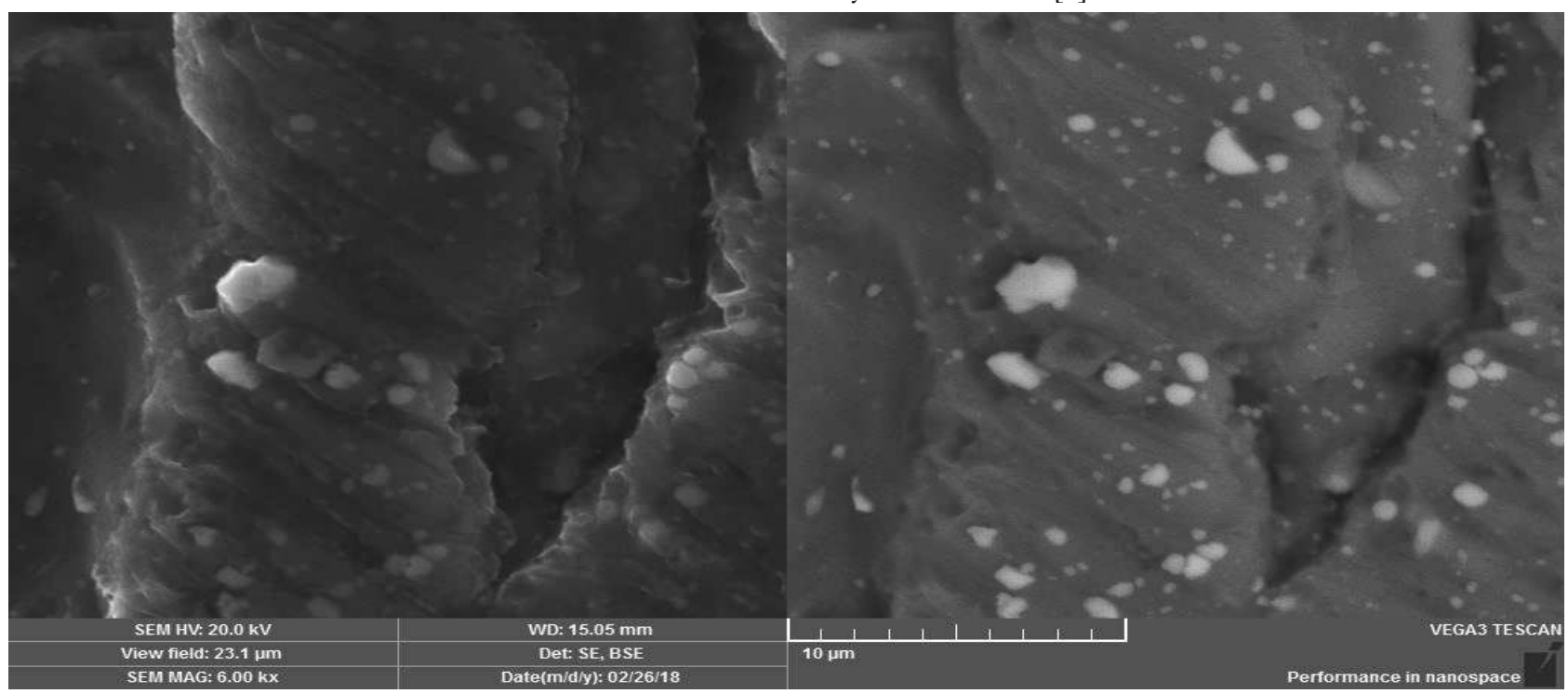

Fig. $\boldsymbol{8}$ Particles composed primarily of $\mathrm{Cr}$ 


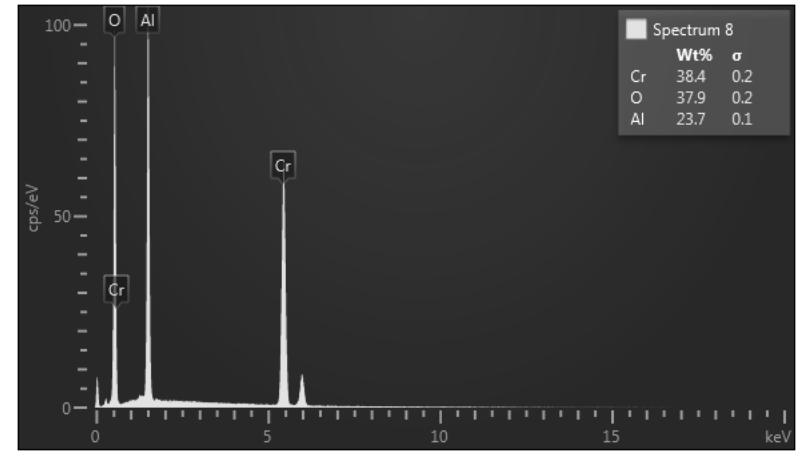

Fig. 9 EDS analysis of particles

\section{Conclusion}

The visible impact of the tensioner wear with the lock nut was in the area of the front face of this component. At this site, foreign particles have been detected. These particles have been trapped on the surface of the tensioner during 180 hours of operation. SEM and EDS methods were used for detection. These particles caused shallow scratches, while some of the particles remained in the surface. These were mainly $\mathrm{Ni}, \mathrm{Cr}, \mathrm{Cu}$ and $\mathrm{Zn}$ based particles in terms of chemical composition. Probably these particles were on the surface of the tensioner from the engine oil in which they are contained. Material and engineering design of this tensioner type seems appropriate. To increase the lifetime of this type of tensioner, it is necessary to check its setting regularly and also to change the oil regularly, which extends the life of the engine. When replacing the tensioner, it is necessary to thoroughly clean the threaded parts to prevent them from being damaged by engine oil particles. These particles have a greater hardness than the base material of the tensioner.

\section{Acknowledgement}

This paper deal was supported by the Slovak Grant Agency KEGA 007TnUAD-4/2017, VEGA grant No. 1/0649/17, VEGA grant No. 1/0589/17. The work was supported by the project „Advancement and support of $R \& D$ for "Centre for diagnostics and quality testing of materials" in the domains of the RIS3 SK specialization", code NFP313010W442.

\section{References}

[1] FIGLUS, T., WILK, A., LIŠČĆK, Š. (2014). Condition monitoring of the cam chain tensioner in the motorcycle engine. In: Vibroengineering PROCEDIA, Vol. 3, published 10 October 2014, pp. 376-379.

[2] MICHNA, Š., LUKÁČ, I., OČENÁŠEK, V., KOŘENÝ, R., DRÁPALA, J., SCHNEIDER, H., MIŠKUFOVÁ, A. and coll. (2005). Encyclopedia of aluminum. Adin, s.r.o. Presov, 2005, p. 720. ISBN 80-89041-88-4.

[3] BOLIBRUCHOVÁ, D., BRŮNA, M. (2017). Impact of the Elements Affecting the Negative Iron-Based Phases Morphology in Aluminium Alloys - Summary Results. In: Manufacturing Technology, Vol. 17, No. 5, pp. 675-679. ISSN 1213-2489

[4] UHRÍČIK, M., PALČEK, P., CHALUPOVÁ, M., ORŠULOVÁ, T. (2017). The Structure of the Aluminium Alloy and Its Influence on the Fatigue Properties. In: Manufacturing Technology, Vol. 17, No. 5, pp. 863-869. ISSN 1213-2489

[5] MACHUTA, J. NOVÁ, I., KEJZLAR, P. (2017). Structure and Mechanical Properties of Aluminium Alloys AlSi10 and AlSi5Mg. In: $\mathrm{Ma}$ nufacturing Technology, Vol. 17, No. 5, pp. 772777. ISSN 1213-2489

[6] LUKÁČ, I., MICHNA, Š. (1999). Atlas of structures and defects in aluminum and its alloys, A separate monograph authors, Deltaprint Děčín 1999, ISBN 80-238-4611-6.

[7] LUKÁČ I., MICHNA Š. (2000). Structure failures of the Al-Si alloys and their identification using fractography, EDX and metallography analyses. Transactions of the Univerzity of Košice 4/2000, pp. 13-19. ISSN 1335-2334

[8] LUKÁČ, I., MICHNA, Š. (2001). Colour Contrast, Strukture and Defects in Aluminium and Aluminium Alloys, In: Cambridge international science publishing, september 2001, Great Britain. ISBN 18 98326-70-3 